\title{
A Research on the Design of FSM Based Vending Machine
}

\author{
V. Prasad, G. Ramya, G. Sandeep, K. Laxmareddy
}

\begin{abstract}
A candy system is a device which apportions topics, as an instance, snacks, beverages, lottery tickets, client gadgets or maybe gold and jewels to customers therefore, after the cash or the customer embeds the card into the tool. Sweet machines are everyday in international places like Japan, Germany, and US and so on conditions of sweet machines is growing little by little due to the cutting side way of life and short. Programmed candy machines primarily based FPGA is more adaptable and quicker machines than CMOS-primarily based. The candy device is predicated upon on FPGA are moreover programmable and can be reinvented whilst within the machine primarily based Embedded we need to alternate the whole engineering of the system on the off hazard that we want to exchange or enhance the form of the system. Within the execution of this paper from a sweet device the usage of the Finite nation gadget (FSM) version is proposed making use of VHDL.FSM demonstrating is the most enormous component in constructing up the proposed candy machine model as this diminishes the vital device. In this undertaking, each MEALY and MOORE device version is applied to display the manner for the explicit that consumer selfcontrol, sitting tight for the addition of coins, conveyance of items and administrations.
\end{abstract}

Watchwords - FSM, VHDL, vending gadget, version MEALY and MOORE, FPGA.

\section{INTRODUCTION}

Sweet device used to apportion an series of devices, for instance, coffee, Snacks and bloodless Drink and so on at the same time as coins is located into it, which is typically brought in trendy shops, railroad stations, workplaces, colleges and distinctive open spots. The essential commercial corporation coin labored machines were provided in London and the United Kingdom used to sell postcards. Programmed sweet machines are step by step available and commonplace experience contrasted with the buy approach for bookkeeping indicates. In recent times, it has a bent to be found anywhere, as an example, in train stations promote train tickets, in schools and workplaces merchant of liquids and bites, in a economic institution as an ATM device and gives even treasured stone and platinum gems to clients. Past CMOS and SED based motor takes greater time than FPGA-based gadget. FPGA-primarily based motor is additionally increasingly adaptable,

Revised Manuscript Received on September 14, 2019.

V. Prasad, Assocate. Prof, Department of ECE, AVN Institute of Engineering and Technology, Hyderabad, Telangana, India. (Email: yenohi007@gmail.com)

G. Ramya, Assist. Prof, Department of ECE, Siddhartha Institute of Technology \& Sciences, Narapally, Ghatkesar, Hyderabad, Telangana, India.

G. Sandeep, Assist. Prof, Department of ECE, Siddhartha Institute of India.

K. Laxmareddy, Assist. Prof, Department of ECE, Siddhartha Institute of Technology \& Sciences, Narapally, Ghatkesar, Hyderabad, Telangana, India. Technology \& Sciences, Narapally, Ghatkesar, Hyderabad, Telangana,

programmable and may be re-customized. Be that as it can, in microcontroller-based motor, at the off hazard that one needs to beautify the plan, it ought to change the entire engineering again but in FPGA customers can virtually extend the amount of items. Our intention might be limited to creating unique fashions for a sweet gadget as depicted beneath and in a while find out the changing speed, time obstacles, power, close by wishes and makes use of motive present inside the FPGA to discover all the greater efficiently and equipment mixed regarding our sweet tool determinations.

This machine additionally bolsters restoration include implies that individuals can pull returned the solicitation and the cash may be returned lower again to the purchaser. Severa superior sweet machines can widely recognized fee or Visas than cash. In the Western worldwide, a few sweet machines giving individual objects, for the maximum part in an open can workplaces. The machines in the women normally promote cushions or tampons.

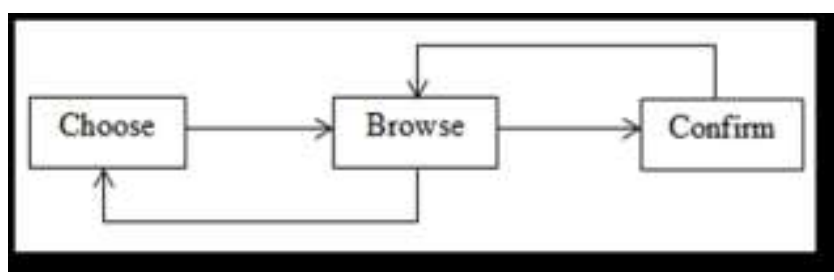

Figure 1: Concept of model

\section{LITERATURE SURVEY}

1. Comparison of different attributes in FSM based Vending Machine

They speak round specific arrangement of guidelines for a candy device as depicted beneath and in a while identifying out the evolving pace, timing trouble, manage, area request and simplicity of use of motive found in FPGA own family an excellent way to look out more and more green and synthesizable this is undercover HDL into genuine element machine with admire to this candy device precise.

Sweet device attributes to be executed is attached as below:

1The tool pulls decrease lower back merchandise of Rs10 as it had been.

2. The gadget can dispense:

Water: Rs 20 (Wi)

Tidbits: Rs 20 (Si)

Soda pop: Rs30 (Ci) 
Three. It has a Cancel key or tab (Cc)

Four. Simply every data might be work in flip

Five. A framework can be disbursed in a unmarried whole clock cycle

6. On the off hazard that greater than Rs 30 is positioned, the coins is consequently this is without physical connection the extra coins return implies lower back

7. Within the event that no information property are dynamic lively, the kingdom framework stays in identical unique that is within the gift country.

Eight. Yields: All build a heartbeat that works the supply contraption:

Ro: return out (all cash within the framework)

So: Snacks out, out10: Rs 10 out

Initially the framework turned into in its set beginning role or scenario which taken into consideration unique $\mathrm{A}$ for the shape reason. Given a contribution of Rs 10 the framework configuration moved in its 2 nd situation which have become state $\mathrm{B}$ related to this thing the dispensing framework is grumbling Rs 10 in its equalization and the customer has 2 choices both to brush aside the dispensing hobby with the contribution of $\mathrm{Cc}$ this is drop which is accessible at the framework or set in another Rs 10 be conscious inside the framework and pass directly to the following scenario which is u. S . D. Presently at this period allotting framework amassed Rs 20 in like manner consumer is capable of pick alternatives among water or snacks the 2 of that are of Rs 20 and in a while cross lower back to its inceptive scenario other than beat Cc (drop) key to complete the activity or aside from set in every different Rs 10 note inside the tool to distribute the soda.

\section{Intelligent espresso merchandising gadget}

A smart meting out framework suits a sensor and actuator set up which made from a portal, rising from an individual's surroundings sensors, and controllers. A door fits a bridge between the device and a usage overseeing on a PDA that is portable alongside Bluetooth. The door gave a few notes associated with the rising from man or woman's environment situations (as an example, cleansing recognition) of the framework from the sensors. The ones messages are sent to the supplication. In interest, the door sends direction messages consisting of the client's inclination at the flavor of espresso to the controllers.

On a technique of the affirmation of deliberation, they building up attractive sensors and three controllers. The dispensing framework and the mechanical assemblies set up within the distributing framework. The attractive sensors are constructed up inside the framework: one is associated with the materials blender and the opposite is related to the frame of the framework. The sensor at the frame is joined to a sensor interface which passes on unflinching information to the door. The sensors reply like a transfer. At the off danger that the blender is disconnected from the body, an unbound taking place takes place. Some thing else, a verified going on occurs. The remoteness of the blender is analyzed to be the cleaning reputation of the framework. The substances blender is an device wherein water, espresso, sugar and fueled espresso half of of and half of include various to make a few espresso.
Wo: Water out, Co: tender drink out

Item shipping: If real sum of money esteem is placed the object can be dropped and if there's any evaluate will amount a good way to be return to customer.

Management: The distributing framework will call for for management if the object can not be carried out inside the framework.

\section{Merchandising machine dependent on the short} message installment

The meting out framework is prevalently gathered of 3 sections: dispensing framework associated cooperate with framework (containing dishing out framework interface plate, strong integrated circuit and GPRS module), GPRS correspondence systems which is probably containing versatile occupying middle of GPRS base station controller, GPRS control bolster hub truly as GPRS spine structures and so on and the manage centre. The distributing framework correspondence interface module is prevalently amassed with of solid integrated circuit and GPRS module, and many others.

The client initially sends the statistics facts to the visitor place of business overseeing attention and in a while the shopping or selling from purchaser consciousness sends returned the information casing to the consumer and the dishing out framework GSM module. The purchaser inputs the data facts outline at the shelling out framework and later on the programmed overseeing dishing out framework handles the records records region to send the overseeing pointers honestly. The records data outline which the GSM module acknowledges is moved to the shopping and selling hobby of consumer popularity to build up the remaining information statistics managing. The fast message installment by acquiring M68HC11 and MC35 and develop it have the errand of the fast message buying and amass it clean to utilize and cope with.

\section{HOBBY OF VENDING MACHINE}

1. On the factor at the same time as the customer places in cash, cash counter tells the control unit, the degree of coins embedded inside the vending machine.

2. On the factor when the purchaser presses the capture to buy the issue that he wishes, the manipulate unit turns on the engine and administers the object if right sum is embedded.

3. Inside the occasion that there's any alternate, device will go back it to the customer.

4. The machine will interest for overhauling when the gadgets are not on hand inside the gadget.

\section{FSM (Finite kingdom gadget) [2] [3]}

In a Finite state system the circuit's yield is characterised in an exchange association of states for example every yield is a state. A nation sign up to maintain the state of affairs of the system and a subsequent $\mathrm{u} . \mathrm{S}$. Intent to disentangle the subsequent state. A yield sign up characterizes the yield of the machine. In FSM based totally machines the device receives reduced as in this the complete calculation can be clarified in a unmarried manner. 
Forms of kingdom machines are:

Coarse device: in this system model, the yield is primarily based upon the existing kingdom just as on the statistics. The MEALY tool model is appeared in determine 2.

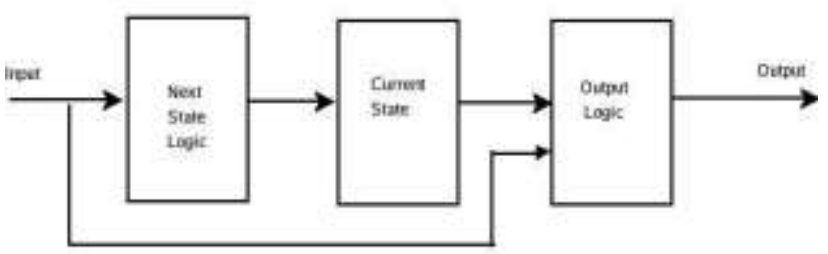

Figure 2: MEALY Machine Model

\section{MOORE Machine:}

In Moore machine model the output only depends on the present state. The MOORE machine model is shown in figure 3 .

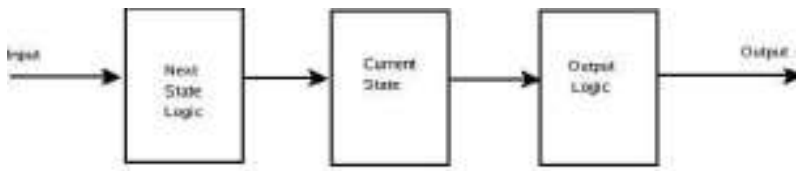

Figure 3: MOORE Machine Model

\section{IMPLEMENTATION OF VENDING MACHINE}

A country outline advanced for the proposed machines that can promote 4 gadgets are coffee, cold beverages, rolls and bites. Four select out (select1, select2, select3, select4) input is taken for desire of gadgets. Select1 applied for the selection of tidbits. So moreover select2, select3, select 4 implemented for coffee, cold drinks and rolls each. Rs_10 and facts rs_20 communicate to rupee 10/ - and 20/ - each phrase. A drop input is also applied even as the consumer needs to tug decrease lower back his solicitation and furthermore the coins can be lower lower back via the yield back. Once extra, the objects and the change is yield. Return and change the vector seven bits extensive. Coins is in/out signal that may be refreshed with the whole mixture of the superb variety of objects conveyed immediately. Sign cash is seven bits huge. Test cash is an interior signal that may be refreshed at every alternate. This sign likewise seven bits wide. On the off threat that the cash is positioned over the all out cash of the item, at that component the change can be lower back thru the signal yield changes. Gadgets with their expenses seemed inside the table 1 . There are additionally two facts signals CLK and reset. The device will deal with the excellent fringe of the clock and returning to the underlying kingdom when the reset capture is squeezed. The proposed candy gadget structured the use of FSM demonstrating and coded in VHDL language. Subtleties of all signal with heading and their depictions are appeared in table 2 .

Table 1: Products with their costs

\begin{tabular}{|c|c|c|}
\hline S.No. & Product & Cost \\
\hline 1. & Cool drinks & $40 /-$ \\
\hline 2. & Snacks & $30 /-$ \\
\hline 3. & Coffee & $10 /-$ \\
\hline 4. & Biscuits & $20 /-$ \\
\hline
\end{tabular}

Table 2: Inputs/Outputs with Remarks

\begin{tabular}{|c|c|c|c|}
\hline NAME & $\begin{array}{l}\text { WID } \\
\text { TH }\end{array}$ & $\begin{array}{l}\text { DIRECT } \\
\text { ION }\end{array}$ & $\begin{array}{c}\text { DESCRIPTI } \\
\text { ON }\end{array}$ \\
\hline CLK & 1 & Input & Clock \\
\hline RESET & 1 & Input & Syn reset \\
\hline SEL1 & 1 & Input & Cool drinks \\
\hline SEL2 & 1 & Input & Snacks \\
\hline SEL3 & 1 & Input & Coffee \\
\hline SEL4 & 1 & Input & Biscuits \\
\hline $\begin{array}{l}\text { CANCE } \\
\text { L }\end{array}$ & 7 & Input & Cancel \\
\hline MONEY & 1 & Inout & Total money \\
\hline RS_10 & 1 & Input & Rupee 10/- \\
\hline RS_20 & 1 & Input & Rupee 20/- \\
\hline $\begin{array}{l}\text { PRODU } \\
\text { CT }\end{array}$ & 1 & Output & Product out \\
\hline $\begin{array}{c}\text { CHANG } \\
\text { E }\end{array}$ & 7 & Output & Extra change \\
\hline $\begin{array}{c}\text { RETUR } \\
\mathrm{N}\end{array}$ & 7 & Output & $\begin{array}{l}\text { Return } \\
\text { money }\end{array}$ \\
\hline
\end{tabular}

\section{DESIGN METHODOLOGY}

The state diagram particularly consists of 4 global locations (user choice, waiting cash insertion, delivery of services and products (if the product is not to be had = '1')). To begin with while the reset button is pressed, the system may be geared up for the patron to choose a product. This $u$. $S$. Is the initial nation of the layout. After this the character will pick a product if you want to be shared. This state can be one select 1 , select 2 , select 3 and pick four. The device may be given only two styles of facts that rupee $10 /$ - and $20 /$-. Let us count on that the person selects the enter SEL1. The primary device will take a look at that whether or not the product is to be had within the machine or no longer. After this the manage unit will glide to the equipped united states, wherein it'll watch for the money to be protected. Then, if the rupee $10 /$ - word blanketed then the tool will visit STATE_1 and waited until the preferred cash inserted. And if the rupee $20 /$ - word inserted the device will flow into to state_2 after which wait till $30 /$ - rupees inserted into the system. Whilst the desired amount protected the tool will visit country light food and snacks is probably added on the output of the product. If the product isn't always to be had within the engine control unit is probably demanded to serve, and after the provider engine gets restarted. This technique is described via way of the use of a drift chart confirmed in parent 4 . 


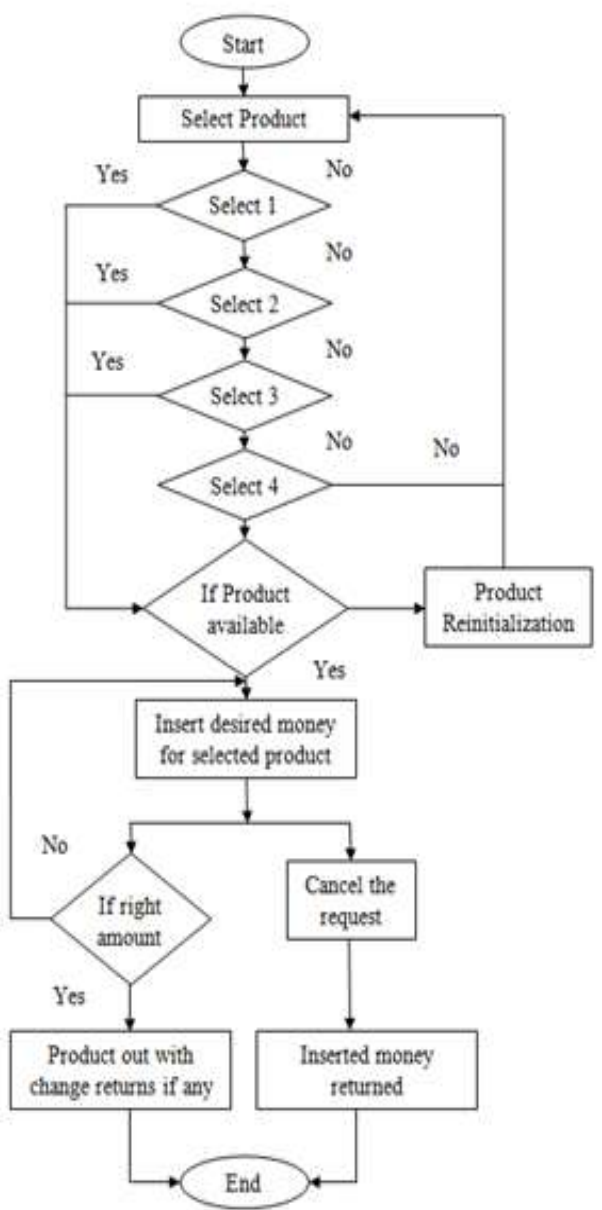

Figure 4: Flowchart for merchandising machines

There's also the added characteristic of a withdrawal request if the user does not need to take the product. While canceling pressed then located the coins may be once more to the individual via the output back. A signal matter cash used to calculate the whole cash positioned within the gadget. And if coins is put over coins from the product then an extra trade could be lower back to the client. The overall quantity of products are taken at a time indicated with the aid of the signal cash. Similarly, the patron can pick out and acquire different merchandise observe the above approach.

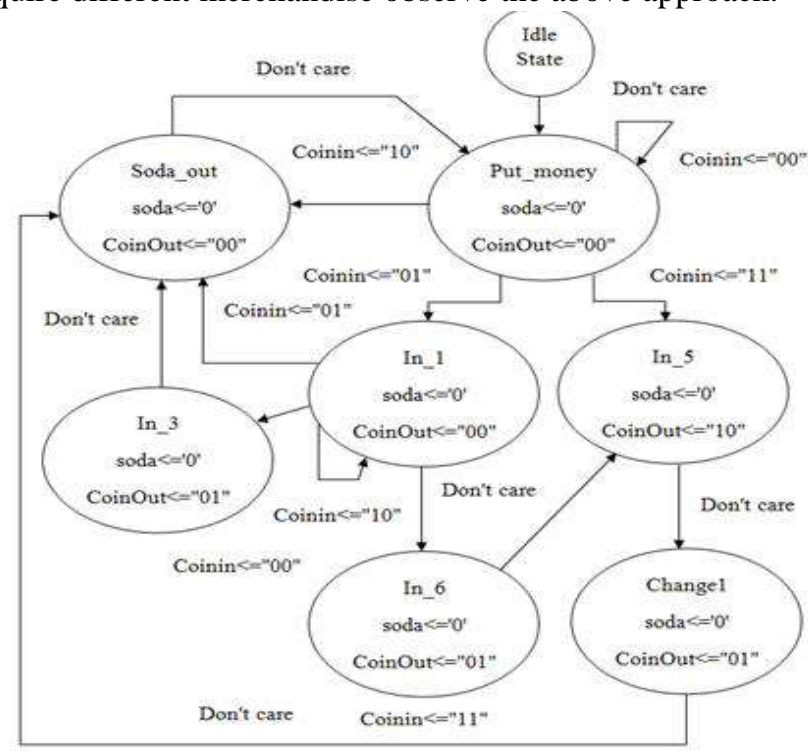

Figure 5 : State Diagram

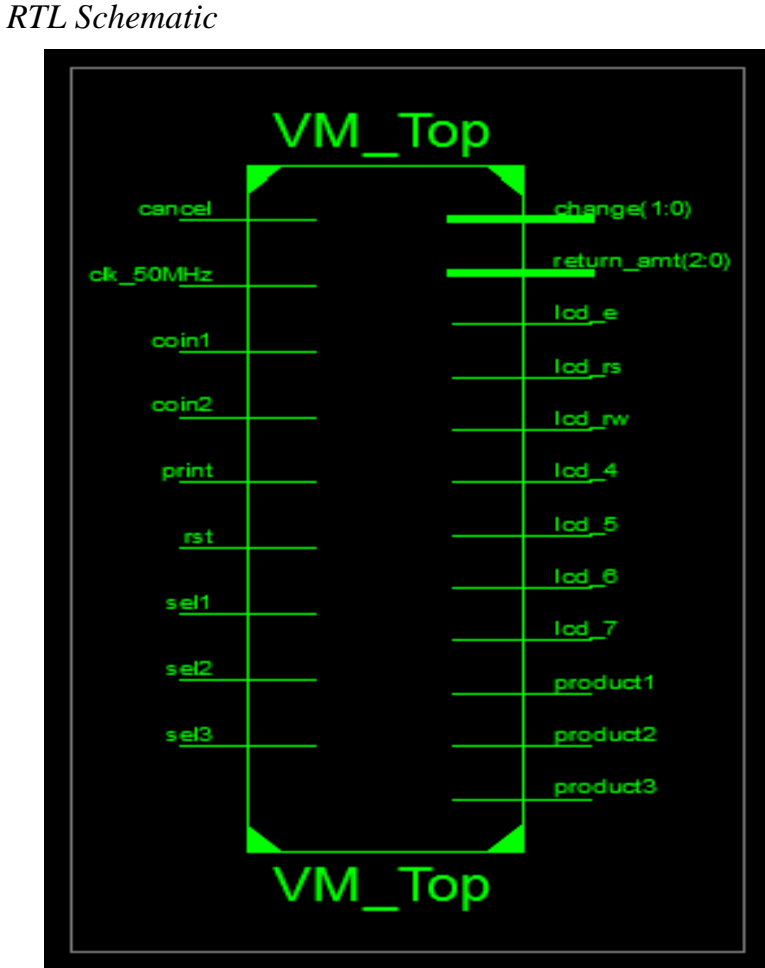

Figure 6: RTL schematic of Vending Machine

\section{SIMULATION RESULTS}

The consumer desires to buy bloodless liquids, at that factor he/she has topush SEL1 button. On the off chance that the item is on the market in machinewill entered waiting_1 nation from the underlying state. Nowthe device will dangle tight for a coin. Clients embed 10/ - rupees

coins, the machine will cross into State2, money_count sign isupdated $10 /$ - and the item is conveyed. Figure 7 suggests theoutput.

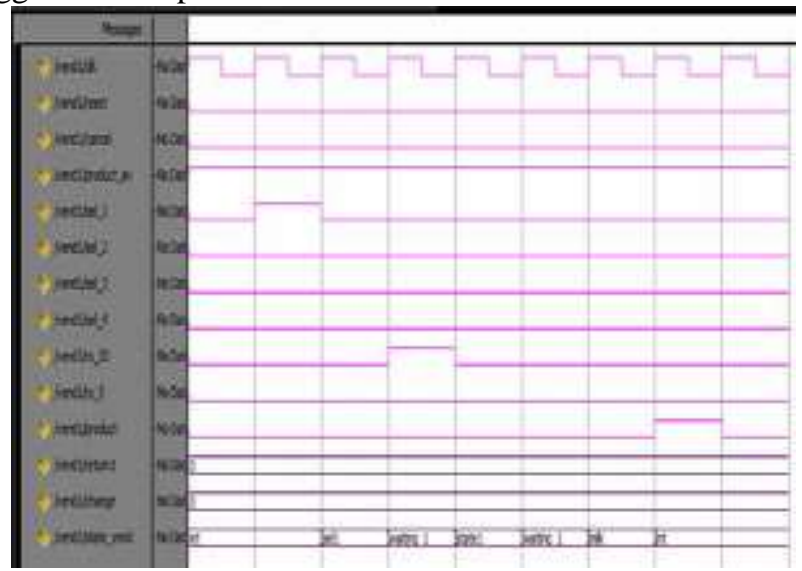

Fig 7: Simulation waveform showing selection of cooldrinks

While the client presses the button sel3, if the product isn't to be had then the engine went into service $3 \mathrm{u} . \mathrm{S}$.. Theservice $3 \mathrm{u} . \mathrm{S}$. Device from shifting to the preliminary state. After that the customer can either wait there for the supply of the requested product or the patron can pick out another product to be had. That is proven in discern eight.

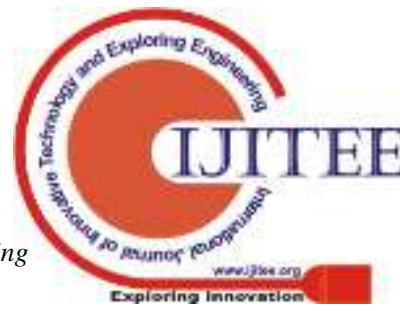




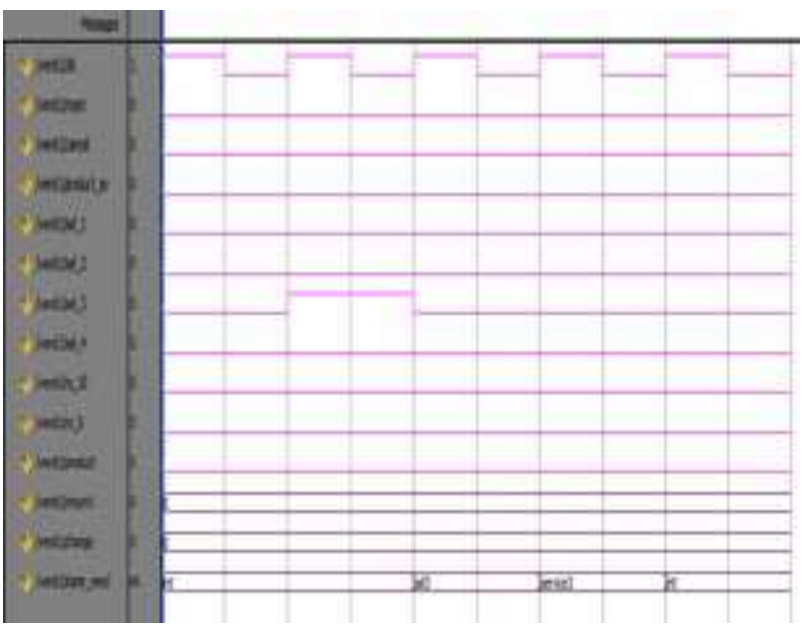

.Parent 8: Simulation of the wave whilst snacks_count $=$ zero

If customers pick product 4 and insert more money and thenhe cancel orders, money placed returnedback to the customer and the product isn't always delivered. Theoutput returen 1 shows the amount of cash lower back again andthe discern 9 suggests the operations designated.

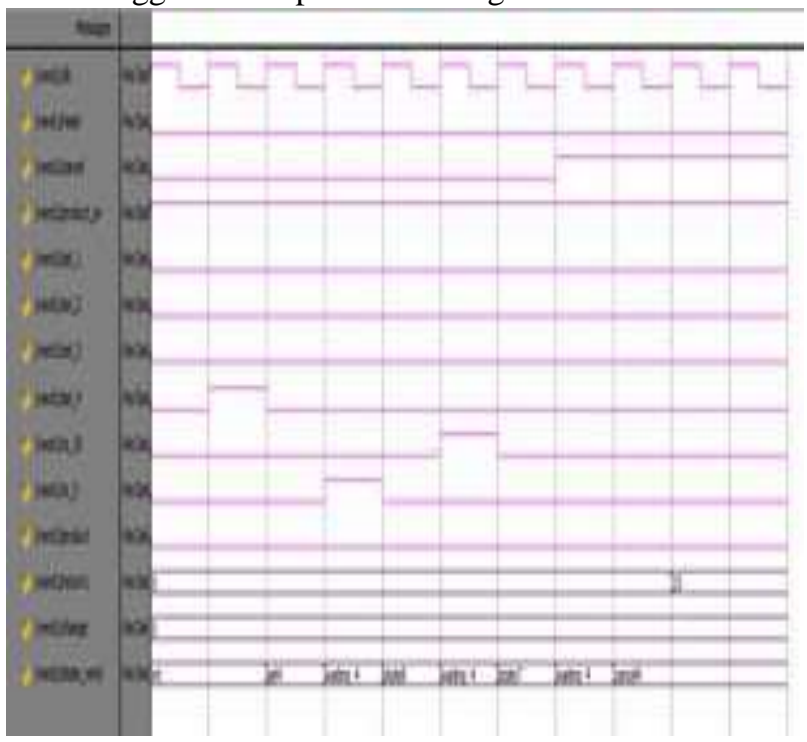

Fig 9: Simulation waveform showing cancel operation

\section{CONCLUSION}

Looked at sweet machines are precise and all are dependent with diverse angles, for instance, territory, energy and postponements because of the time, replacing velocity, and so on. The notable candy system coffee is greater streamlined framework with the consumer's inclination. Since as according to the patron's choice they are able to pick the sum to plan coffee or tea. This framework is advanced with positive elements of intensity, area and time. Additionally make clear with a case of dad intake by means of embeddings a coin into the achievability of shutting the market.

The Future of Work: Vending Machines established alongside those lines can be applied to provide a solitary item, drop the solicitation and auto charging spotlight included via FPGA usage are not given by means of the plan of inserted frameworks later on we will utilize one-of-a-kind strategies for administering severa items concurrently time, which might be more and more useful for the purchaser.

\section{REFERENCES}

1. Ashwag Alrehily, Ruqiah Fallatah and Vijey Thayananthan, "Plan of Vending Machine utilizing Finite State Machine and Visual Automata Simulator" International Journal of Computer Applications (0975 8887) Volume one hundred fifteen - No. 18, April 2015.

2. Vaid Varun, "Correlation of various characteristics in FSM demonstrating primarily based sweet gadget in particular patterns," International Conference on Embedded Systems (ICES), IEEE, 2014

3. Snehal R. Bhoyar, R. D. Ghongade2, "Plan and Implementation of Fingerprint Helping Vending Machine using a microcontroller" International Journal of Computer and Mobile Computing, Vol.Five April - 2017.

4. B Jyothi, Sarah I., A. Srinivas, "Execution of FPGABased Smart Vending Machine" International Journal of Research and Applications in Engineering (IJERA) ISSN: 2248-9622 NATIONAL CONFERENCE on Development, Progress and Trends in Science and Engineering (NCDATES-09 and 10 January 2015).

5. Zhang Wen and Zhang Xin Long (2010), "Plan and Implementation of a sweet machine by using a quick back rub installments" International Conference on Information and Communication Technology Electrical Science, Neijiang, Sichuan, China.Pp.978-981.

6. Biplab Roy and Biswarup Mukherjee (2010) "Plan Coffee Vending Machine utilizing Single Electron Devices" Proceedings of the 2010 International Symposium on Electronic System Design. Pp 38-43.

7. J Clement C. Singh, K Senthil Kumar, Jayanto Gope, Suman Basu and Subir Kumar Sarkar (2007) "Single Electron Device via Automatic Tea Vending Machine" system of the International Conference on Information and Communication Technology Electrical Sciences (ICTES 2007), pp 891 - 896.

8. P.Pradeepa1, T.Sudhalavanya1, K.Suganthi1, N.Suganthi1, Menagadevi M. (2013) "Plan and Implementation Vending Machine Using Verilog HDL". IJAET/Vol.IV/An Issue I/January-March., 2013/51-fifty three.

9. Merrin Ms.Rincy Varkey, Jeeba M Sunny, Design and "Execution of Multi Select Smart Vending Machine" IRACST - International Journal of Computer Networks and Wireless Communications (IJCNWC), ISSN: 22503501 Vol.4, No1, February 2014. 